\title{
Myosin isoenzymes in human hypertrophic hearts. Shift in atrial myosin heavy chains and in ventricular myosin light chains.
}

\author{
M. C. Schaub, C. R. Tuchschmid, T. Srihari and H. O. Hirzel \\ Department of Pharmacology, University of Zürich and \\ Department of Cardiology, University Hospital, Zürich, \\ Switzerland
}

KEY WORDS: Myosin isoenzymes, human cardiac hypertrophy, atrial myosin, ventricular myosin.

The myosin light chain complement and proteolytic peptide patterns of myosin heavy chains were studied by twodimensional and one-dimensional electrophoretic techniques respectively, in a total of 57 samples from ventricular and atrial tissues of normal and hypertrophied human hearts. Hypertrophies were classified haemodynamically as due to pressure-overload and volume-overload. In addition to the occurrence of ventricular light chains in hypertrophied atria we also observed the atrial light chain-1 (ALC-1) in hypertrophied ventricular tissues. On average over $6 \%$ of total light-chain-1 comprised ALC-1 in pressure-overloaded ventricles and around $3 \%$ in volume-overloaded ventricles. In single cases of pressure-overload ALC-1 amounted up to over $20 \%$ of total light chain-1. With regard to the myosin heavy chains limited digestion by two different proteinases produced over 200 clearly resoluble peptides. The absence of any detectable differences in the peptide patterns between myosin heavy chains from normal and hypertrophic tissues of left or right ventricle is in line with the findings of J. J. Schier and R. S. Adelstein (J Clin Invest 1982; 69: 816-825). In atrial tissues however, reproducible qualitative differences in the peptide patterns indicated that during hypertrophy a different type of myosin heavy chains becomes expressed. No differences were seen between the myosin heavy chains from normal left and right atria.

\section{Introduction}

In cardiac muscle the contractile protein myosin is dimeric and consists of two heavy chains $(\mathrm{HC})$ with an approximate molecular weight of 200000 dalton and 4 light chains (LC), a couple of each with a molecular weight of around 21000 and 18000 dalton ${ }^{(1)}$. The existence of myosin isoenzymes in cardiac muscle has been postulated to explain the correlation between myosin ATPase activity as measured in vitro and altered myocardial contractile properties in disease states ${ }^{(2.3)}$. Furthermore, shifts in myosin isoenzyme compcsition with regard to both $\mathrm{HC}$ and $\mathrm{LC}$, have also been observed during ontogenetic development of the heart of man and animals $^{(4-7)}$. In heart ventricles of rodents two types of myosin $\mathrm{HC}$ have been described which are able to form homodimeric and heterodimeric isoenzymes designated in order of decreasing electrophoretic mobility as $\mathrm{V}_{1}=2 \times \mathrm{HC}$-alpha, $\mathrm{V}_{2}=\mathrm{HC}$ alpha + HC-beta and $V_{3}=2 \times$ HC-beta $^{(8)} . \quad V_{1}$ myosin has the highest and $V_{3}$ the lowest ATPase activity ${ }^{(9.10)}$.

Based on comparison of electrophoretic mobilities in normal human ventricle the main isoenzyme is thought to be $V_{3}$ with its low ATPase activity ${ }^{(6.11)}$. The enzymatic centre is known to be comprised within the HC only and the LC seem not to affect the ATPase of isolated myosin ${ }^{(12,13)}$. Thus shifts in the composition of the $\mathrm{HC}$ isoforms are expected to be accompanied by changes in ATPase activities. However, a decline in myofibrillar ATPase activity has been reported for human ventricles in congestive heart failure ${ }^{(14)}$ and severe hypertrophic states ${ }^{(15,16)}$. No change in myosin or myofibrillar ATPase activities nor in the structure of the myosin $\mathrm{HC}$ as judged from their peptide pattern, has been observed in ventricles of patients with hypertrophic obstructive cardiomyopathy ${ }^{(17.18)}$. So in this latter disease there seems to occur no transition in the expression of the isoforms of $\mathrm{HC}$. The lower myofibrillar ATPase activities observed in hyper- 
trophies induced by pressure- or volume-overload is difficult to explain on the grounds of changes in the composition of $\mathrm{HC}$ isoforms, since the normal heart ventricle already contains almost exclusively $V_{3}$ myosin with the lowest ATPase activity. Either a new additional type of myosin $\mathrm{HC}$ may become expressed in some forms of heart diseases or else the LC complement, if its composition changes, might still affect the enzymatic properties of the intact myofibril. Recently it has been reported for skeletal muscle myosin that the $\mathrm{LC}$ indeed play a role in the subtle interaction of the myosin head portions where the $\mathrm{LC}$ are located, with their reaction partner actin and the calcium-sensitive regulatory proteins troponin and tropomyosin ${ }^{(19)}$. Therefore examination of both $\mathrm{HC}$ and $\mathrm{LC}$ is required.

Transition in the LC complement both in human atria and ventricles have been reported recently to occur in response to cardiac pressure overload ${ }^{(20.21)}$. Thereby LC characteristic for ventricle appear in the atrium under pathologic conditions and vice versa. The atrial $\mathrm{LC}_{1}\left(\mathrm{ALC}_{1}\right)$ which occurs in the ventricle of pathologically hypertrophied hearts can also be observed in man and animals to be present in early developmental stages in the foetal ventricle and to disappear after birth ${ }^{(5,22,23)}$. Apparently both heart chambers have retained the ability of transition of their LC complement in the adult. We have therefore undertaken a structural study of both $\mathrm{LC}$ and $\mathrm{HC}$ in ventricles and atria of normal and pathologically hypertrophied human hearts. It was possible to quantify the occurrence of the atrial $\mathrm{ALC}_{1}$ in hypertrophic ventricles in response to pressure- and volume-overload separately. In the right ventricle of children fewer $\mathrm{ALC}_{1}$ emerged in hypertrophy due to pressure-overload. But in an infant at the age of 7 months a large portion of $\mathrm{ALC}_{1}$, which is present normally in the foetal ventricle, was retained in the hypertrophic right ventricle. In contrast, no structural transition was apparent in the myosin $\mathrm{HC}$ from hypertrophic ventricles, but we report here for the first time a change in the peptide pattern of $\mathrm{HC}$ in pathologically hypertrophic atria.

\section{Methods}

Left ventricular endomyocardial biopsy material was obtained from 15 patients by the transseptal route, whereby the King's College Bioptome was advanced through a French-11.5-Brockenbrough catheter from the right femoral vein to the left ventricle. The samples were derived mainly from the lateral apical portion of the left ventricle. Samples from pathological and normal ventricular or atrial tissues were taken during surgery or from autoptic material within $8 \mathrm{~h}$ after death. Cases with left ventricular hypertrophy were classified on haemodynamic grounds as due to pressure-overload with maximal and average pressure gradients above $30 \mathrm{mmHg}$ and valve opening areas below $1.5 \mathrm{~cm}^{2}$, or as due to volume-overload with regurgitation fractions above $40 \%$.

Tissue fragments were stored at $-20^{\circ} \mathrm{C}$ or below until usage. Samples of $1-10 \mathrm{mg}$ were homogenized in the appropriate buffer system and directly applied to electrophoresis. Protein concentrations were determined according to Lowry and coworkers ${ }^{(24)}$. One-dimensional polyacrylamide gel electrophoresis in the presence of sodium dodecyl sulphate (SDS) was carried out according to Laemmli and Favre ${ }^{(25)}$ by using $3 \%$ stacking $(3 \times 18 \mathrm{~cm})$ and $12.5 \%$ separating gels $(13 \times 18 \mathrm{~cm})$ of $1.5 \mathrm{~mm}$ thickness and applying around $25 \mu \mathrm{g}$ protein per sample. For twodimensional gel electrophoresis isoelectric focusing was beforehand carried out in the first dimension according to O'Farrell ${ }^{(26)}$ by using a $(4: 1, \mathrm{v} / \mathrm{v})$ mixture of ampholines $(1.75 \%)$ of the $\mathrm{pH}$ range $5-8$ and 3.5-10 respectively. Polyacrylamide gels (3.64\%) of $11.5 \mathrm{~cm}$ length were prepared in glass tubes $(3 \mathrm{~mm}$ inner diameter and $17 \mathrm{~cm}$ long). For isoelectrofocusing around $120 \mu \mathrm{g}$ of each sample were applied to the top of the pre-electrophoresed gels. The protein in all different gels were visualized by staining in $0.25 \%$ Coomassie Brillant Blue R-250. Destaining of gels and determination of $\mathrm{pH}$ gradient in isoelectric focusing gels were done as before ${ }^{(27)}$.

For isolation of myosin $\mathrm{HC}$, tissue samples were homogenized in $10 \mathrm{vol}$ of $40 \mathrm{mM}$ sodium pyrophosphate $(\mathrm{pH} 7.5$ adjusted with $\mathrm{HCl})$ containing $2 \mathrm{mM}$ dithiothreitol and $5 \mathrm{mM}$ ethylene-glycol-bis (beta-amino ethylether) N,N-tetraacetic acid(28). Immediately before electrophoresis, $4 \mathrm{mM} \mathrm{N}$-ethylmaleimide were added to the sample containing between 200 and $400 \mu \mathrm{g}$ of protein, which were loaded on gels composed of $3 \%$ acrylamide and $0.24 \%$ bis-acrylylcystamine ${ }^{(29)}$. Chamber and gel buffer, pH 8.4, were composed of tris-(hydroxymethyl)aminomethanol (Tris) and (N,N-bis(2hydroxyethyl)glycine) (Bicine) containing $0.1 \%$ SDS as described elsewhere ${ }^{(30)}$. After the electrophoretic run, gels were stained with Coomassie Brillant Blue $\mathrm{R}-250$, subsequently soaked for $15 \mathrm{~min}$ in $20 \%$ methanol followed by $15 \mathrm{~min}$ in the chamber buffer Tris-Bicine $\mathrm{pH} \mathrm{8.4}$. Then bands representing myosin 
HC were excised and the gel slices dissolved by addition of $3-4 \%$ beta-mercaptoethanol. To these samples were added 0.5 vol. bringing the final concentrations similar to those described by Whalen and coworkers ${ }^{(31)}$ : $70 \mathrm{mM}$ Tris, $70 \mathrm{mM}$ Bicine, $0.23 \%$ SDS, $3.5 \%$ beta-mercaptoethanol, $150 \mathrm{mM}$ $\mathrm{NaCl}, 0.03 \mathrm{mM} \mathrm{MgCl}, 48 \mathrm{mM}$ phosphate buffer $\mathrm{pH}$ 6.5. For digestion of $80-100 \mu \mathrm{g}$ of myosin $\mathrm{HC}$ per sample, proteinase from Staphylococcus aureus V8 (EC 3.4.21.19) (Miles, Elkhart, Indiana, USA) and papain (EC 3.4.22.2) (Boehringer, Mannheim, West Germany) were used. The molar ratio of both proteinases to myosin $\mathrm{HC}$ of 200000 dalton molecular weight range from 0.001 up to 0.05 based on the molecular weights of 27700 dalton for the proteinase V8 and 23350 dalton for proteinase papain. Digestion was performed for $30 \mathrm{~min}$ at $37^{\circ} \mathrm{C}$ and the reaction stopped by addition of around 100 fold molar excess of phenylmethylsulphonyl fluoride in the case of the proteinase $\mathrm{V} 8$ and by heating samples for $3 \mathrm{~min}$ at $100^{\circ} \mathrm{C}$ in the case of proteinase papain. The protein digest was then resolved on usual one-dimensional gel electrophoresis in $\operatorname{SDS}^{(25)}$. All peptide patterns were stained by Coomassie Brillant Blue R-250, and in many cases they were, after destaining in $40 \%$ methanol plus $10 \%$ acetic acid, stained again with silver ${ }^{(32)}$ in order to increase sensitivity for visualization of peptides occurring in small quantities.

One-dimensional stained gels and positive films of them were scanned and recorded either by the Gilford Spectrophotometer System 2600 (Gilford Instr. Lab. Inc., Oberlin, Ohio, USA) at $560 \mathrm{~nm}$ or by the LKB 2202 UltroScan Laser Densitometer (LKB-Produkter AG, Bromma, Sweden) at $633 \mathrm{~nm}$. In two-dimensional electrophoresis, firstly, the central absorbance of the spots on the stained gels and on their films was measured with the McBeth TD 504 Densitometer (McBeth Color \& Photometry Div., Newburgh, New York, USA). Secondly, the spots were excised from enlarged prints and weighed. With purified tropomyosin for calibration the average of the two measurements yielded a relationship that was linear from 0.5 up to $14 \mu \mathrm{g}$ of protein per spot. In this way the myosin LC were quantified in each two-dimensional gel relative to tropomyosin. No allowance was made for possible differences in dye-uptake by these proteins. For calculation of the stoichiometry the chemical molecular weights of 21000 dalton for $\mathrm{LC}_{1}, 18000$ for $\mathrm{LC}_{2}$ and 66000 for tropomyosin from both atrial and ventricular tissues were taken. This needs to be mentioned for the apparent molecular weights of the LC in SDS gel electrophoresis are different: 27400 dalton for $\mathrm{LC}_{1}$ and 22600 for $\mathrm{LC}_{2}$ from atrium and 26000 dalton for $\mathrm{LC}_{1}$ and 21000 for $\mathrm{LC}_{2}$ from ventricle $^{(22)}$. The myosin $\mathrm{HC}$ and sometimes also actin were not reliably resolved in the isoelectrofocusing run and could therefore not be quantified.

\section{Results}

VARIATION IN LIGHT CHAIN COMPLEMENT

In support of the finding of Cummins ${ }^{(20)}$ we also observed the occurrence of additional myosin LC in hypertrophied atria which exhibit identical electrophoretic mobilities to those of the ventricle $\mathrm{VLC}_{1}$ and $\mathrm{VLC}_{2}$. Such a ventricular $\mathrm{VLC}_{2}$ was consistently found in atrial tissues from severely hypertrophic hearts. It mostly appeared as double spot due to partial phosphorylation. But occasionally a faint, more acidic, third spot was also visible which is thought to represent a second type of $\mathrm{VLC}_{2}{ }^{(20)}$. Such a second $\mathrm{VLC}_{2}$ type has also been described in several vertebrate species beside $\operatorname{man}^{(33)}$. The $\mathrm{VLC}_{1}$ type occurring in hypertrophic atria was variable and in all cases much reduced in comparison to its $\mathrm{VLC}_{2}$ counterpart. Quantification was therefore not attempted. Quantification of the $\mathrm{VLC}_{2}$ occurring in atria neither proved to be useful since the total amount of the $\mathrm{LC}_{2}$ type varied in both atrial and ventricular tissues of normal as well as hypertrophic hearts. Thereby the $\mathrm{LC}_{2}$ type displayed the tendency to be reduced variably in comparison to the $\mathrm{LC}_{1}$ type.

On the other hand, the $\mathrm{LC}_{1}$ type exhibited a remarkable constancy in amount related to that of tropomyosin (Table 1). Fig. 1 shows the occurrence

Table $I$ Occurrence of atrial $A L C_{1}$ in hypertrophic and normal left ventricles. Total $L C_{1}$ content is given as molar ratio to tropomyosin and $A L C_{1}$ as percentage thereof. The occurrence of $A L C_{1}$ is significant in both forms of hypertrophy at the level of $P<0.01$ in comparison to normal ventricles (mean values are given)

\begin{tabular}{lcccc}
\hline Condition & $\begin{array}{c}\text { Age in } \\
\text { years }\end{array}$ & $\begin{array}{c}\text { Number } \\
\text { of cases }\end{array}$ & $\begin{array}{c}\text { Total LC } \mathrm{LC}_{1} \\
\text { per tropomyosin }\end{array}$ & $\%$ ALC $_{1}$ \\
\hline $\begin{array}{l}\text { Normal } \\
\text { Pressure- }\end{array}$ & $23-66$ & 7 & $2 \cdot 7$ & 0.4 \\
$\begin{array}{l}\text { overload } \\
\text { Volume- } \\
\text { overload }\end{array}$ & $35-79$ & 15 & 3.4 & 6.3 \\
\hline
\end{tabular}




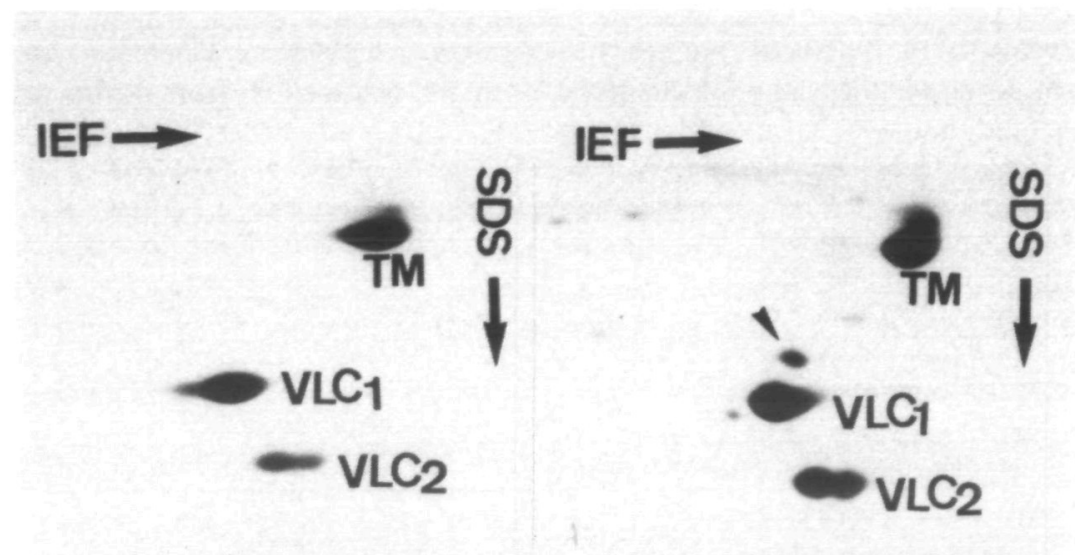

Figure 1 Two-dimensional electrophoresis of total tissue homogenate from left ventricles. Gels are presented with the basic $\mathrm{pH}$ range in isoelectrofocusing (IEF) to the left and decreasing molecular weights from top to bottom in SDS electrophoresis. Left side, normal ventricle of a women at the age of 41 years. Right side, ventricle of a man at the age of 39 years with pressure-overload. TM, mainly alpha-tropomyosin with some little beta-tropomyosin on top; $\mathrm{VLC}_{1}$ and $\mathrm{VLC}_{2}$, ventricular myosin $\mathrm{LC}$; arrow indicates the $\mathrm{ALC}_{1}$ in the hypertrophic ventricle.

of $\mathrm{ALC}_{1}$ in the left hypertrophic ventricle of an adult in comparison to a normal case.

Quantification of the atrial $\mathrm{ALC}_{1}$ occurring in hypertrophic ventricles under pathological conditions seemed useful and led to the results given in Table 1. The total amount of $\mathrm{LC}_{1}$ type is expressed in moles of $\mathrm{LC}_{1}$ per mole of tropomyosin with a molecular weight of 66000 dalton as described in the methods section. The content of the total amount of $\mathrm{LC}_{1}$ did on average not vary significantly between normal and hypertrophic ventricular tissues. There was a slight tendency of higher values of total $\mathrm{LC}_{1}$ in some cases of severe pressure-overload, reaching extremes of 4.0 and 9.6 in two single instances. In these latter cases however, the portion of $\mathrm{ALC}_{1}$ did not exceed 5 and $6 \%$, respectively. On the other hand, the additional $\mathrm{ALC}_{1}$ was significantly increased in hypertrophic $(P<0.01)$ when compared with normal tissue. In pressure-overload the portion of $\mathrm{ALC}_{1}$ varies between 1 and $27 \%$ of total $\mathrm{LC}_{1}$ whereas in volume-overload it ranged between 1 and $5 \%$ only. In normal ventricular tissue $\mathrm{ALC}_{1}$ was seen occasionally as a very faint spot which never exceeded $0.5 \%$ of total $\mathrm{LC}_{1}$.

In four children at the age of 2-7 years with pressure-overload of the right ventricle due to congenital malformation (tetralogy or trilogy of Fallot), the portion of $\mathrm{ALC}_{1}$ in the ventricular tissue ranged between 0.5 and $2.7 \%$. In an infant at the age of 7 months the portion of $\mathrm{ALC}_{1}$ in the ventricle attained $29 \%$. At this age in normal infants the relative content of $\mathrm{ALC}_{1}$ in the ventricle is around $1-5 \%$ and decreases continuously until, at the age of around one year, it has disappeared completely. Price and coworkers ${ }^{(5)}$ have reported a value of $5.7 \%$ for the portion of $\mathrm{ALC}_{1}$ in the normal ventricle of an infant at the age of 8 months.

In two cases with pressure-overload samples were taken separately from both subendocardial and subepicardial muscle layers, in one case of the left ventricle from an adult and in the other from the right ventricle of a child. In both cases the inner and outer muscle layers displayed almost identical LC patterns. In particular, the ventricular $\mathrm{ALC}_{1}$ did not vary significantly between the two layers. Furthermore, in co-electrophoresis of the two muscle layers of one heart, but also in co-electrophoresis of the hearts of the two patients, the ventricular ALC always appeared as one single co-migrating spot.

\section{VARIATION IN HEAVY CHAIN STRUCTURE}

Limited digestion of isolated myosin $\mathrm{HC}$ either with proteinase V8 or with proteinase papain were performed in the presence of $0.23 \%$ SDS under carefully controlled conditions. Examined were 5 cases of left ventricles and 3 cases of left atria from 


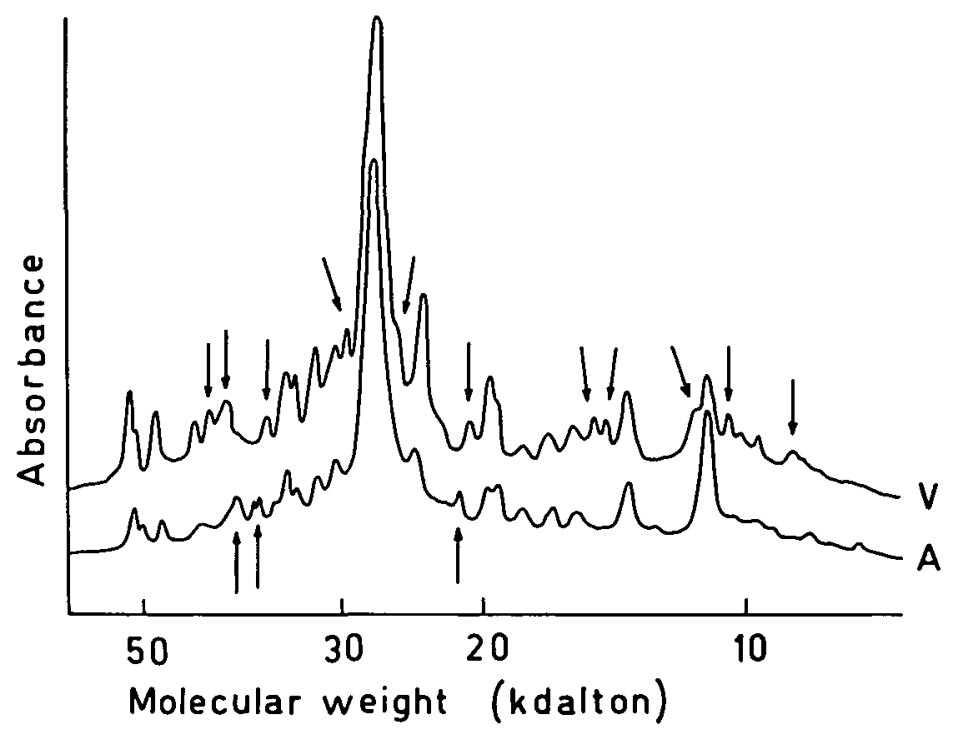

Figure 2 Densitometric traces of electrophoretograms with peptide patterns of myosin $\mathrm{HC}$ from normal left atrial and ventricular tissues after digestion with proteinase V8 (ratio to myosin $\mathrm{HC}, 0.05$ ). Coomassie staining. V, ventricle; A, atrium; arrows indicate qualitative differences (see text in results section).

pressure-overloaded hearts of adults, 2 cases of right ventricles from pressure-overloaded hearts of children, 3 cases of normal left ventricles, 4 cases of normal left atria and 2 cases of normal right atria. In each digestion experiment one or two pathological samples were processed at a time strictly in parallel with a normal one. In separate experiments two normal samples or, alternatively, two or three pathological samples were processed together. Each experiment consisted of a series of parallel digestions with varying concentrations of the proteinases in relation to the concentration of the myosin $\mathrm{HC}$ as indicated in the methods section. Peptide patterns were thus obtained in one-dimensional electrophoretic resolution with both proteinases, in which the majority of peptide bands spread predominantly over the high ( $80-200$ kdalton), middle (30-120 kdalton) or low (10-50 kdalton) molecular weight ranges. In this way well over 200 peptide bands could clearly be distinguished per sample and compared with those of the experimental companions.

Densitometric evaluation was only justified when the patterns to be compared indicated equal degrees of digestion that is the staining intensity of most peptide bands was very similar. As soon as there were different amounts of undigested material between the parallels left at the top of the gel slab, or if in some regions variable staining intensities indicated unequal digestion between them, such experiments were rejected. Particular caution had to be exerted if differences appeared among the protein bands in the high molecular weight range of samples which were processed in parallel. Repetitive experiments proved that in this region transiently occurring peptide bands were occasionally seen in single digestions which could not be reproduced. However, in the middle and low molecular weight ranges differences or, alternatively, no differences at all, between parallels, were clearly recognizable and also reproducible. No differences at all could be detected with either proteinase between the peptide patterns of myosin $\mathrm{HC}$ from right or left ventricles nor between those originating in the outer, middle or inner muscle layers of the left ventricular wall or in the papillary muscles.

The peptide patterns of myosin $\mathrm{HC}$ from atrium and ventricle of a normal adult heart in Fig. 2 show a large number of differences in the low molecular weight range after digestion with proteinase V8. The differences pointed out in Fig. 2 concern peptide bands which occur in one of the two digestion 


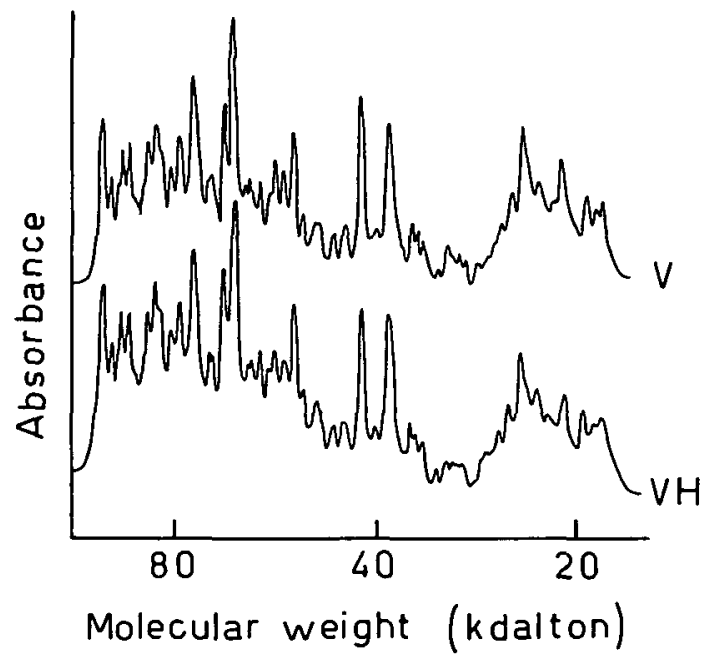

Figure 3 Densitometric traces of electrophoretograms with peptide patterns of myosin $\mathrm{HC}$ from normal and hypertrophic left ventricles after digestion with papain (ratio to myosin HC, 0.02). Coomassie staining. V, normal ventricle of a man at the age of 29 years; $\mathrm{VH}$, ventricle of a man at the age of 79 years with pressure-overload.

patterns only and do not reflect merely quantitative differences of bands existing in both patterns. Fig. 3 comprises peptide patterns of myosin $\mathrm{HC}$ after digestion with papain from normal and hypertrophied left ventricles of adults. The two patterns are almost identical. On close inspection only minute quantitative variation in some of the smallest peptide bands can be detected. In no parallel digestion of myosin $\mathrm{HC}$ from normal and hypertrophic ventricles did we ever see reproducible qualitative differences. This confirms the results of Schier and Adelstein ${ }^{(18)}$ who did neither find differences in the peptide patterns of ventricular myosin from normal and hypertrophic cardiomyopathic hearts. In their case intact native myosin was digested with alphachymotrypsin and papain.

In contrast, qualitative differences could be detected between the peptide patterns of myosin $\mathrm{HC}$ from normal and hypertrophic atrial tissues. The samples shown in Fig. 4 both stem from left atria and were digested with papain. Beside the qualitative differences pointed out by the arrows numbered 1-3, much larger qualitative variations in single bands can be seen than in the two patterns from ventricular myosin $\mathrm{HC}$ in Fig. 3. Such a quantitative variation of a particular band is marked with the arrow

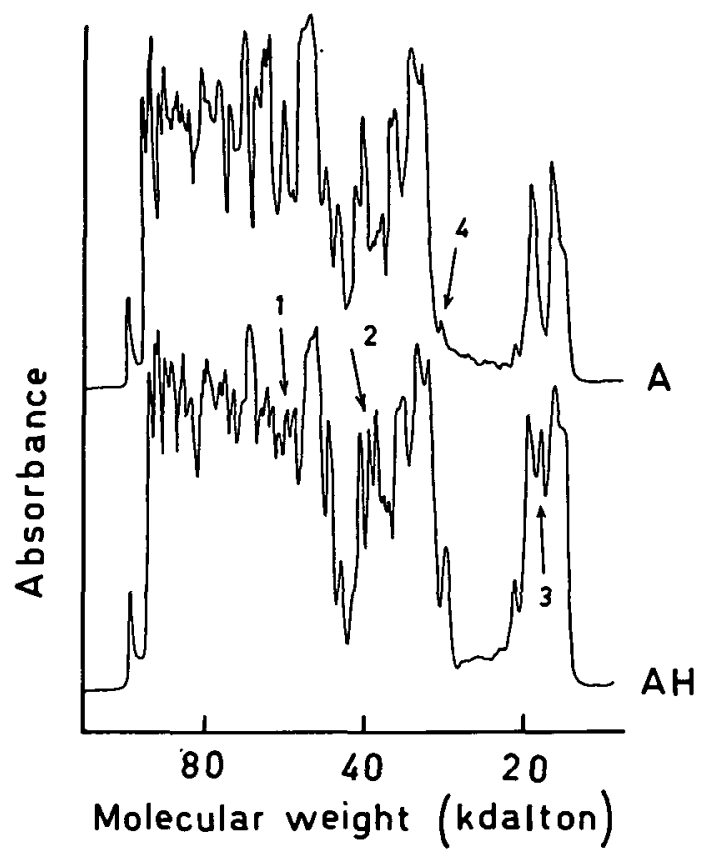

Figure 4 Densitometric traces of electrophoretograms with peptide patterns of myosin $\mathrm{HC}$ from normal and hypertrophic left atria after digestion with papain (ratio to myosin HC, 0.05). Silver staining. A, normal atrium of a woman at the age of 41 years; $\mathrm{AH}$, atrium of a woman of the age of 55 years with pressure-overload; arrows 1-3 indicate qualitative differences; arrow 4 points to a quantitative difference (see text in results section).

number 4 , but immediately to the higher molecular weight side of arrow number 1 is a triplet of bands exhibiting also considerable quantitative variation between the two patterns. Thus unlike the myosin $\mathrm{HC}$ from ventricle, those from atrium do become changed in hypertrophy. Of the 3 hypertrophic left atria examined, two displayed identical peptide patterns between themselves while the third one differed. The patterns of all normal atrial tissues looked identical, even those from right and left atria.

\section{Discussion}

The present study indicates that transitions in the myosin LC complement occur in both atria and ventricles with pathological hypertrophies. In left atria an additional $\mathrm{VLC}_{2}$ is found predominantly

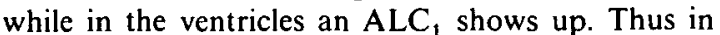
the former case we observed a partial transition of LC in an atrial-ventricular, and in the latter, in 
contrast, in a ventricular-atrial direction. This is somewhat unexpected. It has been speculated the primitive cardiac tube may synthesize mainly an atrial-related type of myosin ${ }^{(5)}$. Under the stimulus of increasing pressure and workload experienced by the newly developing ventricular chamber, ventricular myosin will then come to be produced. In the atrium this sequence of events seems to be maintained when under pathological work-overload ventricular LC become expressed. In the ventricle however, despite an even greater workload, the genetic expression switches back to the primordial type of atrial-like LC. It appears then that with regard to the LC complement which seems to undergo opposing transitions, the isoenzyme expression follows some pre-determined pattern rather than to obey the functional stimulus.

As expounded in the results section quantification of the $\mathrm{LC}_{1}$ type alone led to sensible results. The $\mathrm{LC}_{2}$ type varied in both atria and ventricles in an unpredictable way. It has been reported that this $\mathrm{LC}_{2}$ type characteristic of myosins with low ATPase activity, always yields variable recoveries by various extraction procedures ${ }^{(30)}$. The appearance of $\mathrm{ALC}_{1}$ is highly significant for a pathologically increased workload of the left ventricle. Its appearance is further more pronounced under pressure-overload than under volume-overload. The relatively low level of $\mathrm{ALC}_{1}$ compared to the normal $\mathrm{VLC}_{1}$ content may explain why Klotz and coworkers ${ }^{(34)}$ failed to detect variations in the primary structure of the LC in human hypertrophied left ventricles. In children with pressure-overload of the right ventricle the ventricular-atrial transition of the $\mathrm{LC}_{1}$ type remains even more moderate. However, within the first year of age, where some little $\mathrm{ALC}_{1}$ is still being produced under normal conditions, under pressureoverload the amount of $A L C_{1}$ in the right ventricle is very large indeed. At this young age the large proportion of the atrial $A L C_{1}$ in the right ventricle affected by congenital malformation reflects the persistence of its otherwise declining normal expression.

The total content of the $\mathrm{LC}_{1}$ type in ventricular tissue amounts on average to around 3 moles per mole of tropomyosin. This latter was found to be the most reliable reference protein. In sarcomeric muscles the molar ratio of myosin to tropomyosin was determined to be very close to unity ${ }^{(35)}$. Isolated ventricular myosin contains two moles of $\mathrm{LC}_{1}$ and $\mathrm{LC}_{2}$ each per mole ${ }^{(36)}$. Thus two moles of $\mathrm{LC}_{1}$ type would be expected per mole of tropomyosin.
In total ventricular tissue homogenates we found a constant amount of $\mathrm{LC}_{1}$ type just below three moles per mole of tropomyosin (Table 1), which is very close to the expected value. If the ratio of myosin to tropomyosin is indeed one, then almost all $\mathrm{LC}_{1}$ seem to be bound to myosin. The myosin LC are known to have in heart muscle a somewhat slower turnover rate than the $\mathrm{HC}^{(37)}$, so there might be a small surplus in the pool of LC in the tissue in order to allow all myosin $\mathrm{HC}$ to combine with the appropriate $\mathrm{LC}$ to form intact molecules. We observed a tendency of total $L_{1}$ type to increase in ventricles with hypertrophy due to pressureoverload. The quantitative analyses of the individual cases indicate however, that this increase in total $\mathrm{LC}_{1}$ type was never caused specifically by the additional $\mathrm{ALC}_{1}$ in the ventricle. It rather results from a general stimulation of synthesis of the $\mathrm{LC}_{1}$ type. Should the content of total $\mathrm{LC}_{1}$ be related to that of $\mathrm{HC}$, then myosin would on average not vary drastically in hypertrophic ventricles.

Our new finding with regard to the myosin $\mathrm{HC}$ concerns the occurrence of a $\mathrm{HC}$ isoform in hypertrophied left atria from patients with pressureoverload. In normal hearts the $\mathrm{HC}$, structure as revealed in the peptide patterns was identical in right and left atria. Ventricular myosin $\mathrm{HC}$ are different from normal and pathological atrial myosin $\mathrm{HC}$. In ventricles we never found a difference between normal and hypertrophied tissues. Under the stringent criteria laid down in the results section this means that in the absence of qualitative differences the primary structures of the $\mathrm{HC}$ from normal and pathological ventricles have an extremely high degree of homology or they may indeed be identical. The presence of a new $\mathrm{HC}$ species in hypertrophy in appreciable amounts is excluded by our findings, since a single additional peptide band from such a new species amounting to, or exceeding, $5 \%$ of total protein would not be overlooked in electrophoresis. The peptide patterns of $\mathrm{HC}$ from ventricles could in principle result from a mixture of $\mathrm{HC}$ isoforms. But again such a mixture would have to remain constant in proportion in normal and pathological ventricles since we did not even find significant quantitative differences between them. Electrophoresis of intact native myosin and immunochemical tests have shown that normal human ventricle in fact comprises mainly one isoenzyme, the $V_{3}$ $\operatorname{myosin}^{(6,11)}$.

On the other hand, the qualitative differences in the peptide patterns of $\mathrm{HC}$ from normal and 
pathological atria indicate the occurrence of a new isoform in hypertrophy which is not present in the normal right or left atria. In atrium again a mixture of more than one $\mathrm{HC}$ isoform could be present normally, and the additional quantitative differences under pathological conditions would then indicate furthermore, a shift in the composition of the basic isoenzyme pattern. Or else, if the normal atrium contains only one $\mathrm{HC}$ isoform the quantitative changes may simply reflect its relative decline as the new species arises in hypertrophy.

Alpert and coworkers ${ }^{(38)}$ have demonstrated that hypertrophying heart tissue adapts to slow, economical tension development in response to pressure-overload. In small rodents this is accompanied by a transition of isoenzymes from the normally present $V_{1}$ myosin with high ATPase activity to $V_{3}$ with low activity ${ }^{(9)}$. In $\operatorname{man}^{(6.11)}$ as well as in larger animals $V_{3}$ represents the main isoenzyme in normal ventricles ${ }^{(6.20)}$ and as shown here for man, no transition in $\mathrm{HC}$ isoforms occurs under pathological workload. In atria however, whose myosin has a higher ATPase activity than its ventricular counterpart ${ }^{(39)}$, adaptation to the increased workload by expression of a new isoform of $\mathrm{HC}$ is still possible. Presumably this new myosin isoenzyme has a lower ATPase activity, though this remains to be proven.

In conclusion, we have shown that the expression of isoforms of myosin HC seems to follow functional adaptation in human atria under increased workload while no such isoenzymatic transition takes place in ventricles. On the other hand, the LC complement is regulated independently of the $\mathrm{HC}$ and changes in hypertrophied atria towards the ventricular, and in hypertrophied ventricles towards the atrial composition. Presently we are examining the LC transitions in various forms of heart disease and it seems that some diagnostic value could be derived from the knowledge of the LC pattern.

We are particularly indebted to Professor M. Turina, Department of Surgery, University Hospital, Zürich, for 23 heart samples taken during surgery and to Dr J. Schneider, Department of Pathology, University Hospital, Zürich, for 19 heart samples from autopsy. This work was supported by the Swiss National Science Foundation grant 3.535.79 and 3.152.81, the Swiss Foundation of Cardiology and the Fritz Hoffmann-LaRoche Foundation.

\section{References}

(1) Weeds AG, Frank G. Structural studies on the light chains of myosin. Cold Spring Harbor Symp Quant Biol 1972; 37: 9-14.

(2) Scheur J, Bhan AK. Cardiac contractile proteins: activity and physiological function. Circ Res 1979; 45: $1-12$.

(3) Jacob R, Rupp H, Ebrecht G, Holubarsch C, Kissling $G$. The significance of the isoenzyme pattern of myosin for myocardial mechanics and energetics. Relevance to the definition of cardiac contractility. Z Kardiol 1982; 71: $553-65$.

(4) Whalen RG, Sell SM. Myosin from fetal hearts contains the skeletal muscle embryonic light chain. Nature 1980; 286: 731-3.

(5) Price KM, Littler A, Cummins P. Human atrial and ventricular light-chain subunits in the adult and during development. Biochem J 1980; 191: 571-80.

(6) Lompre AM, Mercadier JJ, Wisnewsky C. et al. Species- and age-dependent changes in the relative amounts of cardiac myosin isoenzymes in mammals. Develop Biol 1981; 84: 286-90.

(7) Chizzonite RA, Everett AW, Clark WA, Jakovcic S, Rabinowitz $M$, Zak $R$. Isolation and characterization of two molecular variants of myosin heavy chain from rabbit ventricle. Change in their content during normal growth and after treatment with thyroid hormone. J. Biol Chem 1982; 257: 2056-65.

(8) Hoh JFY, Yeoh GPS, Thomas MAW, Higginbottom L. Structural differences in the heavy chains of rat ventricular myosin isoenzymes. FEBS Letters 1979; 97 : $330-4$.

(9) Hoh JFY, McGrath PA, Hale PT. Electrophoretic analysis of multiple forms of rat cardiac myosin. Effects of hypophysectomy and thyroxine replacement. J Molec Cell Cardiol 1978; 10: 1053-76.

(10) Pope B, Hoh JFY, Weeds A. The ATPase activities of rat cardiac myosin isoenzymes. FEBS Letters 1980; 118: 202-8.

(11) Clark WA, Chizzonite RA, Everett AW, Rabinowitz M, Zak R. Species correlations between cardiac isomyosins. A comparison of electrophoretic and immunological properties. J Biol Chem 1982; 257: $5449-54$.

(12) Wagner PD, Giniger E. Hydrolysis of ATP and reversible binding to $\mathrm{F}$-actin by myosin heavy chains free of all light chains. Nature 1981; 292: 560-2.

(13) Wagner PD, Weeds AG. Studies on the role of myosin alkali light chains. Recombination and hybridisation of light chains and heavy chains in subfragment-1 preparation. J Mol Biol 1977; 109: 455-73.

(14) Alpert NR, Gordon MS. Myofibrillar adenosine triphosphatase activity in congestive heart failure. Am J Physiol 1962; 202: 940-6.

(15) Leclerq JF, Swinghedauw B. Myofibrillar ATPase, DNA and hydroxyproline content of human hypertrophic heart. Eur J Clin Invest 1976; 6: 27-33.

(16) Swinghedauw B, Schwartz K, Leger JJ. Cardiac myosin. Phylogenic and pathologic changes. Basic Res Cardiol 1977; 72: 254-60.

(17) Maron BJ, Ferrans VJ, Adelstein RS. Isolation and characterization of myosin from subjects with 
asymmetric septal hypertrophy. Circ Res 1977; 40: 468-73.

(18) Schier JJ, Adelstein RS. Structural and enzymatic comparison of human cardiac muscle myosins isolated from infants, adults and patients with hypertrophic cardiomyopathy. J Clin Invest 1982; 69: 816-25.

(19) Wagner PD, Stone DB. Calcium-sensitive binding of heavy meromyosin to regulated actin requires light chain-2 and the head-tail junction. Biochemistry 1983; 22: $1334-42$.

(20) Cummins P. Transitions in human atrial and ventricular myosin light-chain isoenzymes in response to cardiac-pressure-overload-induced hypertrophy. Biochem J 1982; 205: 195-204.

(21) Tuchschmid CR, Srihari T, Hirzel HO, Schaub MC. Structural variants of heavy and light chains of atrial and ventricular myosins in hypertrophied human hearts. In: Cardiac adaptation to hemodynamic overload, training and stress. Steinkopff-Verlag, 1983: 123-8.

(22) Srihari T, Tuchschmid CR, Hirzel HO, Schaub MC. Electrophoretic analyses of atrial and ventricular cardiac myosins from foetal and adult rabbits. Comp Biochem Physiol 1982; 72B: 353-7.

(23) Srihari T, Tuchschmid CR, Schaub MC. Isoforms of heavy and light chains of cardiac myosins from rat and rabbit. Basic Res Cardiol 1982; 77: 599-609.

(24) Lowry OH, Rosebrough NJ, Farr AL, Randall RF. Protein measurement with the Folin phenol reagent. J Biol Chem 1951: 193: 265-75.

(25) Laemmli UK, Favre M. Maturation of the Head of bacteriophage T4. I. DNA packaging events. J Mol Biol 1973; 80: 575-99.

(26) O'Farrell PH. High resolution two-dimensional electrophoresis of proteins. J Biol Chem 1975; 250: 4007-21.

(27) Srihari T, Wiehrer W, Pette D, Harris BG. Electrophoretic analysis of myofibrillar proteins from the body wall muscle of Ascaris suum. Mol Biochem Parasitol 1981; 3: 71-82.

(28) Rupp $H$. The adaptive changes in the isoenzyme pattern of myosin from hypertrophied rat myocardium as a result of pressure overload and physical training. Basic Res Cardiol 1981; 76: 79-88.

(29) Hansen JN. Electrophoresis of ribonucleic acid on a polyacrylamide gel which contains disulfidecrosslinkages. Anal Biochem 1976; 76: 37-44.

(30) Weeds AG. Light chains from slow-twitch muscle myosin. Eur J Biochem 1976; 66: 157-73.

(31) Whalen RG, Schwartz K, Bouveret P, Sell SM, Gros F. Contractile protein isozymes in muscle development; identification of an embryonic form of myosin heavy chain. Proc Nat Acad Sci USA 1979; 76: 5197-201.

(32) Wray W, Boulikas T, Wray VP, Hancock R. Silver staining of proteins in polyacrylamide gels. Analyt Biochem 1981; 118: 197-203.

(33) Westwood SA, Perry SV. Two forms of the P-light chain of myosin in rabbit and bovine hearts. FEBS Letters $1982 ; 142: 31-4$.

(34) Klotz C, Leger JJ, Elzinga M. Comparative sequence of myosin light chains from normal and hypertrophied human hearts. Circ Res $\overline{1982}$; 50 : $201-9$.

(35) Potter JD. The content of troponin, tropomyosin, actin and myosin in rabbit skeletal muscle myofibrils. Arch Biochem Biophys 1974; 162: 436-41.

(36) Pfister M, Schaub MC, Watterson JG, Knecht M, Waser PG. Radioactive labeling and location of specific thiol groups in myosin from fast, slow and cardiac muscles. Biochim Biophys Acta 1975; 410: 193-209.

(37) Zak R. Metabolism of myofibrillar proteins in the normal and hypertrophic heart. Basic Res Cardiol 1977; 72: 235-40.

(38) Alpert NR, Mulieri LA, Litten RC. Functional significance of altered myosin adenosine triphosphatase activity in enlarged hearts. Am J Cardiol 1979; 44: 947-53.

(39) Yazaki Y, Ueda S, Nagai R, Shimada K. Cardiac atrial myosin adenosine triphosphatase of animals and humans. Circ Res 1979; 45: 522-7. 